and drivers of the Earth system to Atlantic circulation and hence to the risk of extreme rainfall in the UK. Many of these drivers appear to have been contributing to a large-scale synoptic situation conducive to flooding in the UK in DJF1314. We remain confident that improved modelling of such drivers will improve our ability to interpret and predict both long-term and year-to-year variations in flood risk. However, we are particularly careful in our Perspective article not to attribute DJF1314 rainfall events to any specific driver. Instead, the purpose of our study was to highlight that it is important to correctly model known teleconnections to Atlantic circulation if we are to understand and predict changing flood risks. That said, as van Oldenborgh et al. ${ }^{2}$ correctly note, an ability to predict flood risk should not be confused with capability to predict individual flood events: the enormous importance of chance should always be acknowledged in any discussion of our chaotic weather.

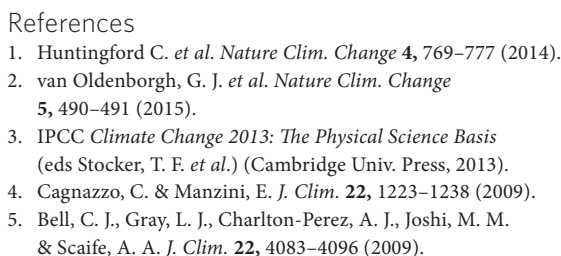

Chris Huntingford ${ }^{1 \star}$, Terry Marsh ${ }^{1}$

Adam A. Scaife ${ }^{2}$, Elizabeth J. Kendon², Jamie Hannaford', Alison L. Kay',

Mike Lockwood ${ }^{3}$, Christel Prudhomme', Nick S. Reynard', Simon Parry', Jason A. Lowe ${ }^{2}$, James A. Screen ${ }^{4}$,
Helen C. Ward', Malcolm Roberts', Peter A. Stott ${ }^{2}$, Vicky A. Bell', Mark Bailey', Alan Jenkins ${ }^{1}$, Tim Legg ${ }^{2}$, Friederike E. L. Otto ${ }^{5}$, Neil Massey ${ }^{5}$, Nathalie Schaller ${ }^{5}$, Julia Slingo ${ }^{2}$ and Myles R. Allen ${ }^{5,6}$

${ }^{1}$ Centre for Ecology and Hydrology, Wallingford, Oxfordshire OX10 8BB, UK. ${ }^{2}$ Met Office Hadley Centre, FitzRoy Road, Exeter, Devon EX13PB, UK. ${ }^{3}$ Department of Meteorology, University of Reading, Earley Gate, Reading RG6 6BB, UK. ${ }^{4}$ College of Engineering, Mathematics and Physical Sciences, Harrison Building, Streatham Campus, University of Exeter, North Park Road, Exeter EX4 4QF, UK. ${ }^{5}$ Oxford University Centre for the Environment, University of Oxford, South Parks Road, Oxford OX13QY, UK. ${ }^{6}$ Atmospheric, Oceanic and Planetary Physics, Clarendon Laboratory, Parks Road, Oxford OX13PU, UK. *e-mail: chg@ceh.ac.uk

\title{
CORRESPONDENCE:
}

\section{Tidal river management in Bangladesh}

To the Editor - The study by Auerbach et al. ${ }^{1}$ advances understanding of the drivers of flood risk in natural and embanked regions of the coastal and tidal regions of Bangladesh. The quantification of sedimentation rates and how effectively periodic opening and closing of polders may result in elevation recovery is valuable in the context of reducing the vulnerability of coastal Bangladesh to flooding in the twenty-first century.

However, we are surprised at the authors' apparent lack of awareness of the long-practiced protocol called tidal river management (TRM) and its successful implementation for over a decade in coastal Bangladesh ${ }^{2,3}$. TRM involves the periodic cutting and closing of polders to accelerate land accretion (or reclamation). TRM as a concept has been around since the 1990s and has been practised or analysed by many local stakeholder entities such as the Institute of Water Modelling of Bangladesh for elevation recovery in several (embanked) regions in coastal Bangladesh. Thus, the management strategy advocated by Auerbach et al. ${ }^{1}$ is not so innovative.

In summary, we commend the authors' quantitative work on understanding flood risk on embanked polder regions. However, the Letter could be more cognizant of previous studies and could have benefited by learning from local wisdom to potentially make their research more useful to the local stakeholders ${ }^{4}$.
References

1. Auerbach, L. W. et al. Nature Clim. Change 5, 153-157 (2015).

2. Haque, K. N. H., Chowdhury, F. A. \& Khatun, K. R. in Land and Disaster Management Strategies in Asia (ed. Ha, H.) Ch. 13 (Springer, 2015)

3. Khadim, F. K., Kar, K. K., Halder, P. K., Rahman M. A. \& Morshed, A. K. M. M. J. Wat. Resour. Protect. 5, 953-961 (2013).

4. Hossain, F. et al. Bull. Am. Meteorol. Soc. 95, 1201-1207 (2014)

Faisal Hossain', Zahirul Haque Khan ${ }^{2}$ and C. K. Shum ${ }^{3}$

${ }^{1}$ Department of Civil and Environmental Engineering, University of Washington, Seattle, 98195 Washington, USA. ${ }^{2}$ Coast, Ports, Estuary Division, Institute of Water Modelling (IWM), Dhaka 1206, Bangladesh. ${ }^{3}$ School of Earth Sciences, Ohio State University, Columbus, Ohio 43210, USA. *e-mail: fhossain@uw.edu

\section{Reply to 'Tidal river management in Bangladesh'}

Auerbach et al. reply - We appreciate the opportunity to address tidal river management (TRM), as raised by Hossain and colleagues ${ }^{1}$. We are aware of TRM but made the decision not to include it in our Letter ${ }^{2}$ on flood risk on the GangesBrahmaputra tidal delta plain for the following reasons.

First, our Letter ${ }^{2}$ concerns a major disaster that displaced $>100,000$ people and flooded an anthropogenically degraded landscape for nearly two years. These circumstances, and our finding that decimetres of sandy, saline sediment unsuitable for agriculture were deposited, do not lead to a simple endorsement of TRM.

Second, TRM presents neither a simple engineering solution nor one that is socially or politically straightforward. Beyond the TRM implementations noted by Hossain and colleagues ${ }^{1}$, there have been well-documented failures resulting from both engineering challenges ${ }^{3}$ and lack of proper social discourse ${ }^{4}$. Although these occurrences do not discount the potential benefits of $\mathrm{TRM}^{5-7}$, they do preclude an unqualified prescription in the context of our Letter.

Third, sites where TRM has been used lie $>50 \mathrm{~km}$ inland of Polder 32 - where the physical environment is considerably different, with reduced tidal energy and less saline surface waters. Furthermore, the area of TRM test sites is about a third of the size of Polder 32, and together these areas comprise $<1 \%$ of the $5,000 \mathrm{~km}^{2}$ of southwest Bangladesh. Thus to consider the application of TRM across the region is premature. 